\title{
Endovascular Thrombectomy for Low ASPECTS Large Vessel Occlusion Ischemic Stroke: A Systematic Review and Meta-Analysis
}

\author{
Jose Danilo B. Diestro (D), Adam A. Dmytriw (D), Gabriel Broocks, Karen Chen, \\ Joshua A. Hirsch, Andre Kemmling, Kevin Phan, Aditya Bharatha
}

\begin{abstract}
Background: The current American Heart Association guidelines for acute ischemic stroke reserve Grade 1A recommendation for the use of endovascular thrombectomy (EVT) for patients with an Alberta Stroke Program Early Computed Tomography Score (ASPECTS) of $\geq 6$. Objective: We aim to determine the safety and efficacy of EVT for large vessel occlusion ischemic stroke patients with low ASPECTS (5 or less). Methods: Medline, Cochrane Central Register of Controlled Trials, and ClinicalTrials.gov were searched for studies appraising the outcomes of EVT for low ASPECTS ischemic stroke. A meta-analysis of proportions compared the clinical outcomes of patients undergoing EVT and those receiving best medical therapy only. Results: Nine studies $(1,196$ patients) were included. There was a trend $(\mathrm{p}=0.11)$ toward a higher rate of symptomatic intracranial hemorrhage (sICH) in the EVT group (9.2\%; 95\% CI 6.1-13.6; I $\left.\mathrm{I}^{2} 53.37 \%\right)$ compared to the medical group (5.5\%; 95\% CI 3.7-8.1; $\left.\mathrm{I}^{2} 0 \%\right)$. There was no difference $(\mathrm{p}=0.41)$ in the pooled 90 -day mortality of EVT patients $\left(30.7 \%\right.$; $95 \%$ CI $\left.21.7-41.5 ; \mathrm{I}^{2} 84.23 \%\right)$ and medical patients $\left(36.6 \%\right.$; 95\% CI 26.4-48.1; $\left.\mathrm{I}^{2} 76.2 \%\right)$. EVT patients had better ( $\left.\mathrm{p}=0.001\right)$ 90-day outcomes, with $27.7 \%(95 \%$ CI $21.8-34.5 ; \mathrm{I}^{2} 62.08 \%$ ) of patients attaining a modified Rankin Scale of $0-2$ compared to only $3.7 \%$ (95\% CI $2.3-5.9 ; \mathrm{I}^{2} 87.21 \%$ ) in the medical group. Conclusions: This meta-analysis demonstrates a trend in higher sICH among low ASPECTS patients undergoing EVT. Despite this, a significant proportion of this subset of patients still achieved good functional outcomes at 90 days. Randomized trials are necessary to substantiate this result as significant bias is inherent in the observational studies included in this review.
\end{abstract}

RÉSUMÉ : La thrombectomie endovasculaire destinée à des patients victimes d'accident ischémique ayant obtenu de faibles scores à l'échelle ASPECTS pour ce qui est de l'occlusion de leurs grandes artères cérébrales. Contexte: Les lignes directrices actuelles de l'American Heart Association quant aux accidents ischémiques aigus considèrent que l'utilisation de la thrombectomie endovasculaire (TE) pour des patients ayant obtenu à l'échelle ASPECTS (Alberta Stroke Program Early CT Score) un score de $\geq 6$ constitue une recommandation de niveau 1A, c'est-à-dire une forte recommandation. Objectif: Nous entendons déterminer la sécurité et l'efficacité de la TE pour des patients victimes d'un accident ischémique aigu qui ont obtenu, pour leurs grandes artères, un faible score à l'échelle ASPECTS (5 ou moins), laquelle constitue une mesure d'occlusion. Méthodes: Pour trouver des études évaluant l'efficacité de la TE chez ce type de patients, nous avons interrogé les bases de données suivantes : Medline, Cochrane Central Register of Controlled Trials et ClinicalTrials.gov. De plus, nous avons effectué une méta-analyse de proportions afin de comparer l'évolution de l'état clinique de patients ayant subi une TE à l'évolution de l'état clinique d'autres patients n'ayant reçu seulement que le meilleur traitement médical. Résultats: Au total, 9 études incluant 1196 patients ont été retenues. Une tendance $(p=0,11)$ à un taux d'hémorragie intracérébrale symptomatique (HICS) plus élevée a été notée dans le groupe de patients ayant subi une TE $\left(9,2 \%\right.$; IC 95 \%, 6,1 \% - 13,6 \%; $\left.\mathrm{I}^{2} 53,37 \%\right)$ en comparaison avec l'autre groupe $\left(5,5 \%\right.$; IC $\left.95 \%, 3,7 \%-8,1 \% ; \mathrm{I}^{2}=0 \%\right)$. Aucune différence n'a émergé $(p=0,41)$ entre le taux de mortalité combiné après 90 jours (pooled 90-day mortality) des patients ayant subi une TE $\left(30,7 \%\right.$; IC $95 \%, 21,7-41,5 \%$; $\left.\mathrm{I}^{2} 84.23 \%\right)$ et celui des autres patients $\left(36,6 \%\right.$; IC $\left.95 \%, 26,4 \%-48,1 \% ; \mathrm{I}^{2} 76,2 \%\right)$. Mentionnons enfin que les patients ayant bénéficié d'une TE ont donné à voir au bout de 90 jours ( $p=0,001$ ) une évolution plus satisfaisante de leur état clinique. En effet, 27,7\% d'entre eux (IC 95 \%, 21,8 - 34,5\%; $\mathrm{I}^{2} 62,08 \%$ ) ont obtenu un score de 0 à 2 à l'échelle modifiée de Rankin alors qu'ils n'étaient seulement que 3,7 \% (IC 95\%, 2,3 -5,9\%; $\mathrm{I}^{2}$ 87,21\%) dans l'autre groupe. Conclusions: Cette méta-analyse montre ainsi une tendance à des taux d'HICS plus élevés parmi des patients ayant subi une TE et ayant obtenu de

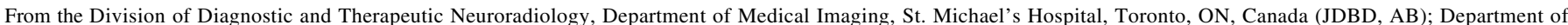

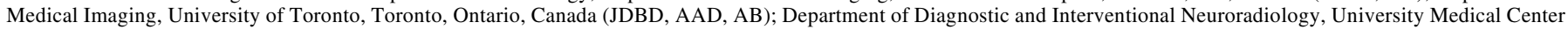

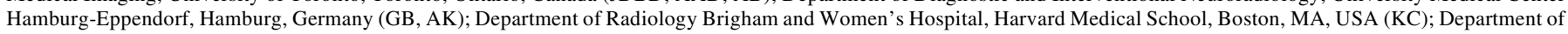

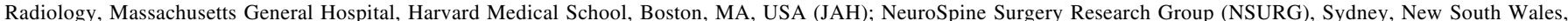

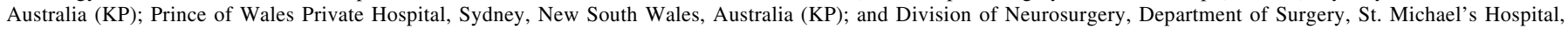
University of Toronto, Toronto, Canada (AB)

Received March 23, 2020. Final Revisions Submitted April 10, 2020. Date of Acceptance April 11, 2020.

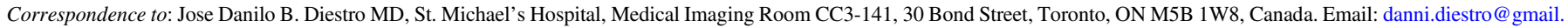
com 
faibles scores à l'échelle ASPECTS. Malgré cela, une proportion notable de ce sous-ensemble de patients a quand même obtenu au bout de 90 jours de bons résultats en termes de capacité fonctionnelle. Des essais cliniques randomisés demeurent nécessaires pour étayer cette constatation car un biais important est inhérent aux études observationnelles inclues dans cette étude.

Keywords: ASPECTS, Stroke, Thrombectomy, Meta-analysis

doi:10.1017/cjn.2020.71

Can J Neurol Sci. 2020; 47: 612-619

\section{BACKGROUND}

Ischemic stroke is a leading cause of mortality and preventable disability. ${ }^{1,2}$ The treatment of acute debilitating large vessel occlusion ischemic stroke has been revolutionized in the wake of multiple randomized controlled trials that show superior clinical and radiologic outcomes with endovascular thrombectomy (EVT) compared to medical management including IV thrombolysis. ${ }^{3-7}$ These trials had stringent inclusion and exclusion criteria, but given the uniformity of the outcomes, with low numbers need to treat in the 2-4 range, it is important to determine whether additional subgroups of patients excluded from the original trials might also benefit. Emerging evidence supports expanded treatment window to at least 24 hours, increasing the number of stroke patients that may benefit from EVT. ${ }^{8}$ However, Grade 1A recommendations in the current guidelines still reserve the use of mechanical thrombectomy for ischemic stroke patients with Alberta Stroke Program Early Computed Tomography Score (ASPECTS) of $>5$, in an attempt to exclude patients with "large core" established infarcts which were assumed to be unlikely to benefit. ${ }^{9}$ Reperfusion of large infarcts is thought to be potentially futile and may increase risk for symptomatic intracranial hemorrhage $(\mathrm{sICH}) .{ }^{10}$

However, recent pooled data offered by the Highly Effective Reperfusion evaluated in Multiple Endovascular Stroke Trials (HERMES) collaboration investigating EVT for large vessel occlusion ischemic stroke revealed a consistent benefit associated with the intervention across all infarct core volumes, including those considered to be large core infarcts $(\geq 70 \mathrm{cc})$. These benefits were especially apparent in young patients. ${ }^{11}$ In a separate metaanalysis that included additional trials, the HERMES collaboration highlighted an exploratory analysis which showed the benefit of EVT even in patients with ASPECTS between 3 and 5 , but not for those with very low ASPECTS (0-2). ${ }^{12}$ The analysis also showed an increased sICH rate of $19 \%$ for low ASPECTS $(<6)$ patients who underwent mechanical thrombectomy, which is more than four times the $4.4 \%$ sICH rate found across all ASPECTS. ${ }^{12,13}$ As studies emerging from the HERMES collaboration were based on trials ${ }^{3-5}$ that sought to exclude those with large core infarcts, the numbers for this subgroup of patients with low ASPECTS is understandably low.

With a number needed to treat of only 2.6 for a reduction in 1 modified Rankin Scale (mRS) point, ${ }^{13}$ EVT has definitively transformed the management of large vessel occlusion ischemic stroke in carefully selected patients. However, if the recommended American Heart Association Stroke guidelines ${ }^{9}$ for EVT were to be strictly applied in clinical practice, a substantial number of patients, including the subset of patients with low ASPECTS, would be left with the dismal natural history of large vessel occlusion stroke with $73.5 \%{ }^{13}$ of patients being dead or dependent (mRS of 3-6) at 90 days.
Data derived from retrospective observational studies from EVT registries that operate outside the strict confines of a trial can provide insight regarding the outcomes in this subset of patients who undergo EVT. Several observational studies ${ }^{14-17}$ looked into the outcomes of patients with ASPECTS less than or equal to 6 . Their findings unanimously suggest that this subgroup of patients may have benefit comparable to those with higher ASPECTS. Ohta et al. ${ }^{18}$ demonstrated that this benefit is even more apparent when these low ASPECTS patients undergoing EVT are compared to a group who receive medical therapy alone. The strongest evidence comes from a subgroup analysis of a randomized controlled trial (THRACE) that showed a favorable trend (36\% vs $26 \%$ ) toward good (0-2) 90-day mRS in patients who undergo EVT and intravenous thrombolysis compared to those receiving intravenous thrombolysis only for patients with ASPECTS of 0-4. ${ }^{19}$ Despite the low number $(n=57)$ of patients with very low ASPECTS in this trial, the results were certainly encouraging.

Through this meta-analysis, we aim to explore the data on the clinical outcomes of patients with low ASPECTS $(<6)$ undergoing EVT, with emphasis on sICH rate, mortality rate and 90-day mRS, mortality rate and $\mathrm{sICH}$ rate.

\section{Methods}

The guidelines and outlines set by Preferred Reporting Items for Systematic reviews and Meta-Analyses (PRISMA) ${ }^{20}$ and Meta-analyses Of Observational Studies in Epidemiology ${ }^{21}$ were adhered to in this systematic review and meta-analysis. Data supporting the results of the study are available from the corresponding author upon reasonable request.

\section{Search Strategy, Information Sources, and Study Selection}

MEDLINE, Cochrane Central Register of Controlled Trials, and ClinicalTrials.gov were reviewed for pertinent literature published from January 1, 2015 up to April 13, 2019 in line with the PRISMA guidelines. The terms "endovascular" "thrombectomy" "ASPECTS", and "stroke" were used in various combinations to identify the appropriate studies for the systematic review. The MEDLINE search was done in both MeSH Terms and All Fields. The search on Cochrane was limited to Cochrane Reviews and Trials. On ClinicalTrials.gov, only completed, suspended, and terminated studies were sought. To ensure that all eligible studies were included in the systematic review, authors of studies with incomplete data were contacted by email and hand searching through the references of selected studies was also done.

\section{Study Eligibility}

Studies were included based on the following criteria: (1) inclusion of patients who underwent endovascular therapy 


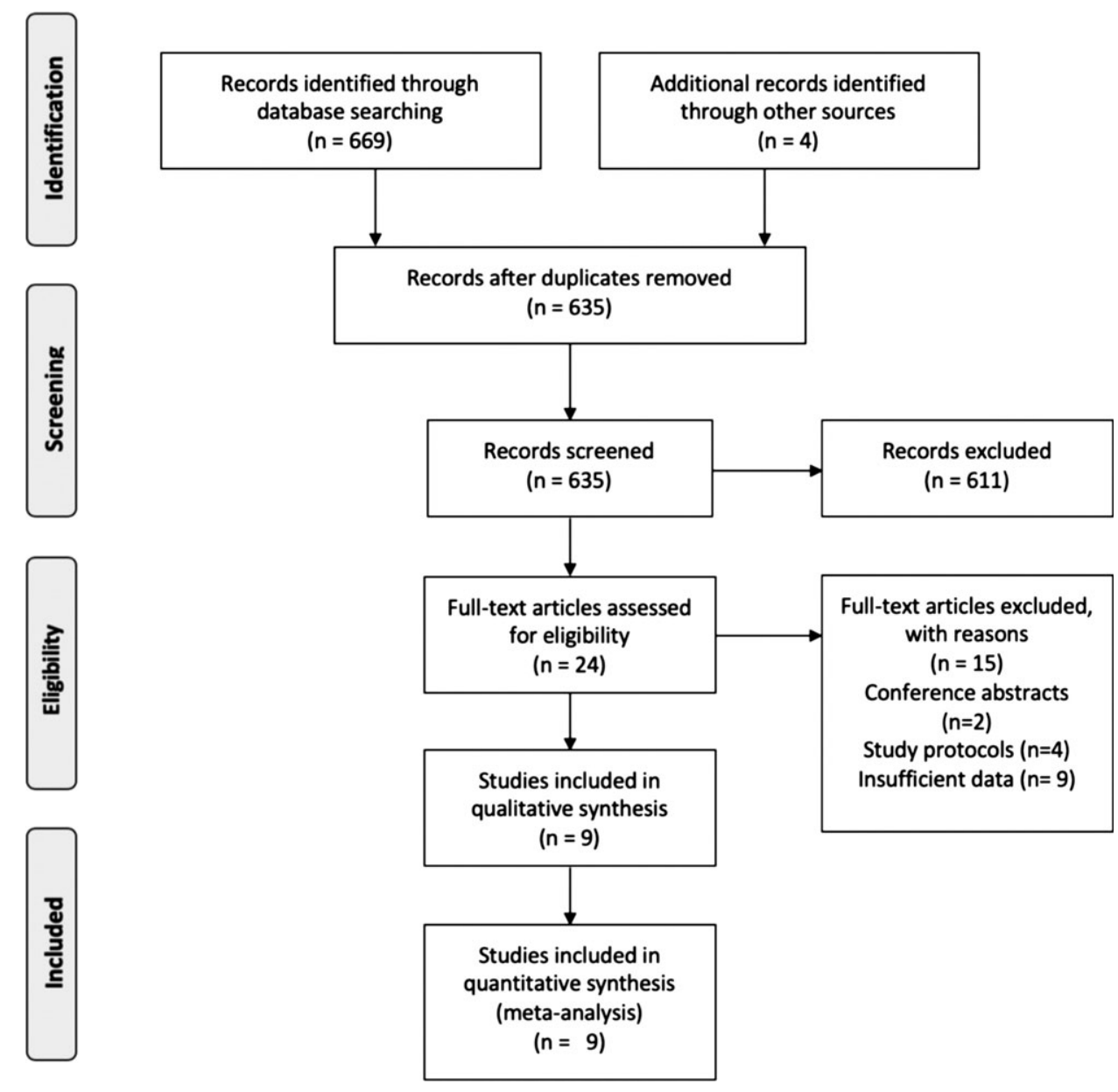

Figure 1: Flow diagram of study selection patients.

for acute large vessel occlusion ischemic stroke involving the anterior circulation with an ASPECTS of 5 or less on baseline imaging with cranial computed tomography (CT) or magnetic resonance imaging (MRI) scan; (2) description of 90-day mRS outcomes and sICH, (3) written in the English language. Studies with small sample size $(<10)$, involving the pediatric population and conference abstracts, were excluded from the review.

\section{Risk of Bias}

All the studies included were observational studies. Five studies were single-group cohorts that only included patients undergoing EVT and therefore deemed to have high risk of bias. Nonetheless, the quality of these studies was assessed using an evaluation tool for case series ${ }^{22}$ (see Table 1 in Supplemental Digital Content). The remaining four studies with data for both EVT and best medical therapy arms were rated according to the Newcastle-Ottawa Assessment Scale for Cohort Studies ${ }^{23}$ (see Table 2 in Supplemental Digital Content). These five studies had low degree of bias.

\section{Data Collection Process and Data Items}

Two physicians (JBD and KP) independently reviewed the selected studies for quality and extracted the following data from the full text articles: title, author, study period, year of publication, number of patients, patient characteristics (age, sex), ASPECTS range, 90-day $\mathrm{mRS}$, and sICH. We requested for additional details by emailing the authors for studies with incomplete data. All data were tabulated in a spreadsheet (Microsoft Excel for Mac v16.28) for analysis. Any disagreements with data extraction and article appraisal were settled by a third independent reviewer (AAD). If the study did not provide means and standard deviations, we estimated these means and standard deviations from the median and range values if these data were not available. ${ }^{24}$ The primary outcomes for this study were 90-day mRS scores, mortality, and the rate of sICH. Data on patients who underwent best medical therapy were included. The best medical therapy group includes large vessel occlusion patients who received standard of care stroke management which include but are not limited to anticoagulation, antiplatelet therapy, and thrombolysis.

\section{Statistical analysis and Synthesis of Results}

A meta-analysis of proportions was conducted for the available main perioperative and postoperative variables. Firstly, to establish variance of raw proportions, a logit transformation was applied. To incorporate heterogeneity (anticipated among the included studies), transformed proportions were combined using DerSimonian-Laird random effects models. Finally, the pooled estimates were back-transformed. Heterogeneity was evaluated using Cochran's Q and $\mathrm{I}^{2}$ test. All analyses were performed using 
Table 1: Characteristics of included studies

\begin{tabular}{|c|c|c|c|c|c|}
\hline $\begin{array}{l}\text { First author, publication } \\
\text { year, study type }\end{array}$ & Study period, region & $\begin{array}{l}\text { No. of patients with } \\
\text { ASPECTS } 5 \text { or less) }\end{array}$ & $\begin{array}{c}\text { No. of patients } \\
\text { undergoing EVT/No. of } \\
\text { patients undergoing BMT }\end{array}$ & $\begin{array}{l}\text { Neuroimaging used (CT } \\
\text { or MRI) for ASPECTS }\end{array}$ & Devices used \\
\hline Kakita $^{26}$ & 2014-2016, Japan & 504 & $172 / 332$ & Both & Not specified \\
\hline Jiang $^{27}$ & 2010-2015, China & 89 & $36 / 53$ & Both & Solitaire \\
\hline Mourand $^{28}$ & 2009-2015, France & 108 & $60 / 48$ & MRI & Solitaire, Trevo, Catch, Merci \\
\hline Broocks $^{29}$ & 2015-2017, Germany & 117 & $66 / 51$ & CT & Not specified \\
\hline Song $^{30}$ & 2016-2018, China & 19 & $19 / \mathrm{NA}$ & MRI & Solitaire \\
\hline Kaesmacher $^{31}$ & 2017-2018, Multinational & 237 & $237 / \mathrm{NA}$ & Both & Solitaire \\
\hline Manceau $^{32}$ & 2010-2016, France & 82 & 82/NA & MRI & Solitaire and ACE \\
\hline Haussen $^{33}$ & 2010-2015, USA & 26 & $26 / \mathrm{NA}$ & $\mathrm{CT}$ & Not specified \\
\hline $\mathrm{Li}^{34}$ & 2014-2016, China & 14 & $14 / \mathrm{NA}$ & CT & (Mostly) Solitaire \\
\hline
\end{tabular}

ASPECTS, Alberta Stroke Program Early CT Score; EVT, endovascular thrombectomy; BMT, best medical therapy; CT, computed tomography; MRI, magnetic resonance imaging; NA, not applicable

Table 2: Baseline characteristics of patients

\begin{tabular}{l|c|c|c}
\hline Demographics & EVT & $\begin{array}{c}\text { Best medical } \\
\text { therapy }\end{array}$ & p-Value \\
\hline Age (Years) & 67.1 & 71.4 & 0.15 \\
\hline Females (\%) & 41.8 & 49.3 & 0.047 \\
\hline Dyslipidemia (\%) & 31.7 & 23.7 & 0.34 \\
\hline Hypertension (\%) & 57.7 & 56.0 & 0.953 \\
\hline Prior cerebral infarction (\%) & 6.8 & 5.5 & 0.96 \\
\hline Diabetes (\%) & 17.7 & 37.3 & 0.007 \\
\hline NIHSS Score (mean) & 18.6 & 20.0 & 0.22 \\
\hline Onset to admission time (mins) & 165 & 181 & 0.68 \\
\hline IV rTPA (\%) & 49.7 & 49.0 & 0.82 \\
\hline Location of occlusion & & & \\
\hline ICA (\%) & 31.8 & 24.1 & 0.64 \\
\hline M1 (\%) & 55.4 & 58.2 & 0.823 \\
\hline M2 (\%) & 15.4 & 5.4 & 0.04 \\
\hline Tandem (\%) & 18.2 & 18.8 & 0.93 \\
\hline ICA, internal carotid artery; & & & \\
\hline
\end{tabular}

ICA, internal carotid artery; NIHSS, National Institutes of Health Stroke Scale; rTPA, recombinant tissue plasminogen activator.

the metafor package for R version 3.01 (www.R-project.org). p-Values $<0.05$ were considered statistically significant.

\section{Results}

\section{Study Selection}

A total of 635 studies were identified through electronic database searches and other sources. After exclusion of duplicate or irrelevant references, 24 potentially relevant articles were retrieved. After detailed review, nine studies remained for assessment. The flow diagram of the study selection process is presented in Figure 1.

\section{Characteristics of Studies and Patients}

The nine studies included in the analysis were published from 2016 to 2019. All were observational studies utilizing prospectively collected stroke registry data. Apart from the study by Kakita et al., ${ }^{25}$ all the included studies were retrospective. Four of the nine studies compared low ASPECTS patients undergoing EVT and best medical therapy. The other five studies were observational studies that only looked at outcomes of patients undergoing EVT. A total of 1,196 patients with ASPECTS of 5 or less were included in the analysis. Of these, 712 patients underwent EVT with best medical therapy, while 484 patients only received best medial therapy. The summary of the characteristics of the studies are summarized in Table 1.

Both groups are similar in all baseline characteristics, except for more females in the best medical therapy group $(49.3 \%$ vs $41.8 \%, \mathrm{p}=0.047)$ and more diabetic patients in the best medical therapy group $(37.3 \%$ vs $17.7 \%, p=0.007)$. Of the four studies that indicated the median ASPECTS, two studies ${ }^{25,34}$ had significantly lower ASPECTS in the best medical therapy group (ASPECTS 3) compared to the EVT group (ASPECTS 5). There were more distal middle cerebral artery (M2 segment) occlusions in the best medical therapy group compared to the EVT group $(15.4 \%$ vs $5.4 \%, \mathrm{p}=0.04)$. The pooled onset to reperfusion time in the EVT arm was 324 minutes (95\% CI 275.949-372.346; $\mathrm{I}^{2} 92.58 \%$ ). The baseline characteristics of the patients are summarized in Table 2.

\section{Symptomatic Hemorrhage, 90-day Mortality, and 90-day Functional Outcomes}

Patients in the EVT arm had a pooled recanalization rate of 72.3\% (95\% CI 61.5-81.0; $\mathrm{I}^{2} 82.21 \%$ ). There was a trend toward a higher rate of $\mathrm{sICH}$ in the EVT group $(9.2 \%$; $95 \%$ CI 6.1-13.6; $\left.\mathrm{I}^{2} 53.37 \%\right)$ compared to the best medical therapy group $(5.5 \%$; 95\% CI $\left.3.7-8.1 ; \mathrm{I}^{2}=0 \%\right)$ but this did not reach statistical significance $(\mathrm{p}=0.11)$ (see Figure $2 \mathrm{~A})$. There was no difference $(\mathrm{p}=0.41)$ in the pooled 90 -day mortality of EVT patients $\left(30.7 \%\right.$; $95 \%$ CI $\left.21.7-41.5 ; \mathrm{I}^{2} 84.23 \%\right)$ and best medical therapy patients $\left(36.6 \%\right.$; 95\% CI 26.4-48.1; $\mathrm{I}^{2} 76.2 \%$ ) (see Figure 2B). 
A

Studies

Kakita EVT

Jiang EVT

Broocks EVT

Song EVT

Kaesmacher EVT

Manceau EVT

Li EVT

Subgroup EVT ( $\left.{ }^{\wedge} 2=53.37 \%, P=0.036\right)$
Mourand EVT
$0.037(0.017,0.079)$

$0.194(0.096,0.355)$

$0.050(0.016,0.144)$

$0.121(0.062,0.224)$

$0.105(0.026,0.337) \quad 2 / 19$

$0.072(0.045,0.113) 17 / 236$

$0.085(0.041,0.168) \quad 7 / 82$

$0.214(0.071,0.494) \quad 3 / 14$

$0.092(0.061,0.136) 53 / 676$

$0.049(0.029,0.081) 14 / 287$

$0.075(0.029,0.184) \quad 4 / 53$

$0.063(0.020,0.177) \quad 3 / 48$

$0.059(0.019,0.167) \quad 3 / 51$

$0.055(0.037,0.081) 24 / 439$

$0.079(0.058,0.107) \quad 77 / 1115$
Estimate $(958 \mathrm{CI})$

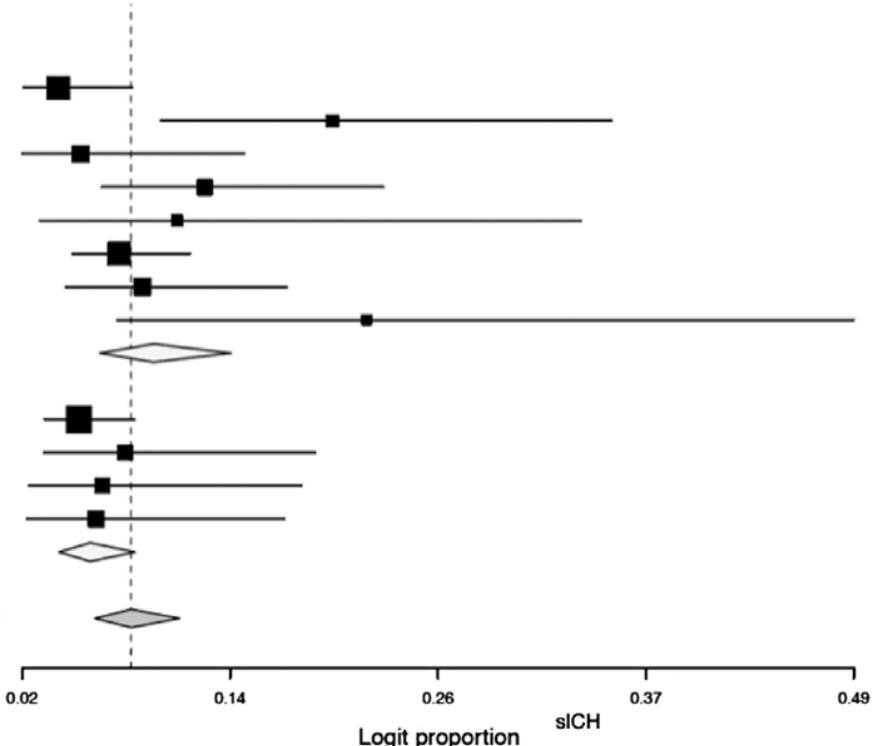

Logit proportion sICH

B

Studies

Kakita EVT

Jiang EVT

Mourand EVT

Broocks EVT

Song EVT

Kaesmacher EVT

Manceau EVT

Haussen EVT

Li EVT

Subgroup EVT (I^2=84.23 \%, P=0.000)

Kakita BMT

Jiang BMT

Mourand BMT

Broocks BMT

Subgroup BMT (I^2=76.2 \% , P=0.006)

Overall (|^2=81.09\%, P=0.000) $\begin{array}{llc}\text { Estimate }(958 \mathrm{CI}) & \text { Ev/Trt } \\ 0.140(0.095,0.200) & 24 / 172 \\ 0.333(0.200,0.500) & 12 / 36 \\ 0.250(0.157,0.374) & 15 / 60 \\ 0.227(0.142,0.343) & 15 / 66 \\ 0.158(0.052,0.392) & 3 / 19 \\ 0.407(0.346,0.471) & 96 / 236 \\ 0.463(0.359,0.571) & 38 / 82 \\ 0.308(0.162,0.505) & 8 / 26 \\ 0.643(0.376,0.843) & 9 / 14 \\ 0.307(0.217,0.415) & 220 / 711 \\ & & \\ 0.268 & (0.223,0.318) & 89 / 332 \\ 0.434 & (0.308,0.569) & 23 / 53 \\ 0.479 & (0.343,0.618) & 23 / 48 \\ 0.333(0.218,0.472) & 17 / 51 \\ 0.366(0.264,0.481) & 152 / 484 \\ 0.327(0.260,0.401) & 372 / 1195\end{array}$

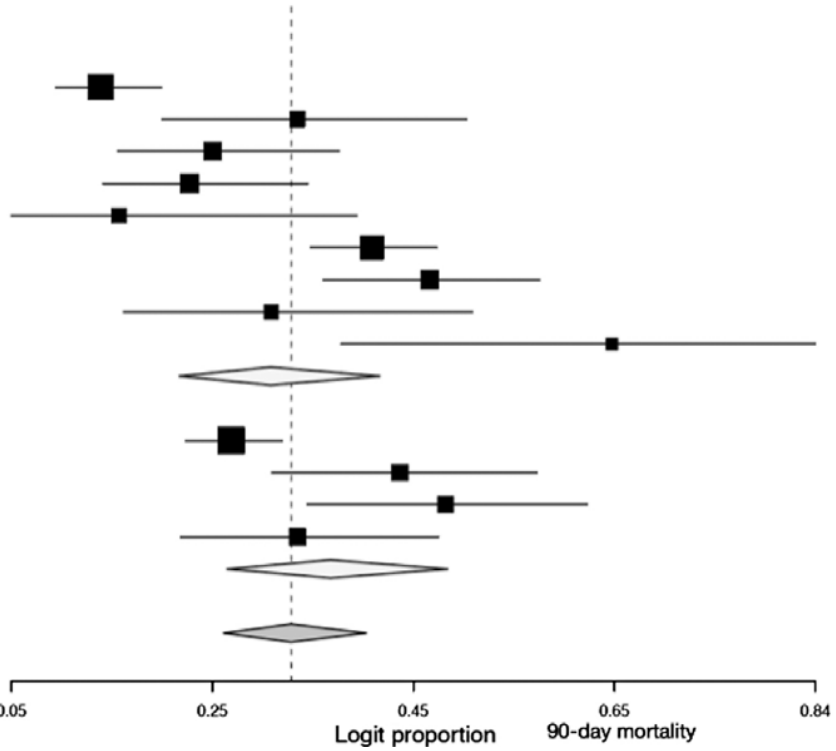

Figure 2: Safety of endovascular thrombectomy (EVT) for low ASPECTS patients. (A) Forest plot of pooled proportion of patients with symptomatic intracranial hemorrhage for EVT and best medical management (BMT). (B) Forest plot of pooled proportion of 90 -day mortality for endovascular therapy (EVT) and best medical therapy (BMT); The estimate proportion of each trial corresponds to the middle of the squares and the horizontal line shows the 95\% confidence interval (CI). For each group, the sum of the statistics, along with the summary proportion, is represented by the middle of the solid diamonds. Weighted data were pooled following logit transformation for proportions. A test of heterogeneity between the trials within a subgroup is also given adjacent to the summary statistics. CI, confidence interval; Evt, events; Trt, treatment sample size.

Patients who underwent EVT had significantly better $(\mathrm{p}=0.001)$ 90-day outcomes, with $27.7 \%$ (95\% CI 21.8-34.5; $\mathrm{I}^{2}$ 62.08\%) of patients attaining an $\mathrm{mRS}$ of 0-2 compared to only $3.7 \%$ (95\% CI $2.3-5.9 ; \mathrm{I}^{2} 87.21 \%$ ) of patients in the best medical therapy (see Figure 3). The EVT groups all have moderate to high heterogeneity $\left(\mathrm{I}^{2}>50 \%\right)$.

\section{Discussion}

\section{Summary of Evidence}

Our review demonstrates that for patients with low ASPECTS who are considered to have very little remaining salvageable brain tissue, there is a trend toward higher rates of sICH for patients who undergo EVT. Despite this, significantly more patients in the EVT group attain good functional outcomes (mRS of 0-2) at 90 days. However, as we will later discuss, there are important limitations of the study because all the studies included were observational in nature.

Compared to the HERMES collaboration meta-analysis ${ }^{35}$ featuring the five landmark trials ${ }^{3-7}$ for EVT in large vessel occlusion ischemic stroke, our meta-analysis showed higher rates of SICH, mortality, and worse outcomes at 90 days. These are likely because most of the studies included in the HERMES metaanalysis excluded patients with low ASPECTS and/or large 


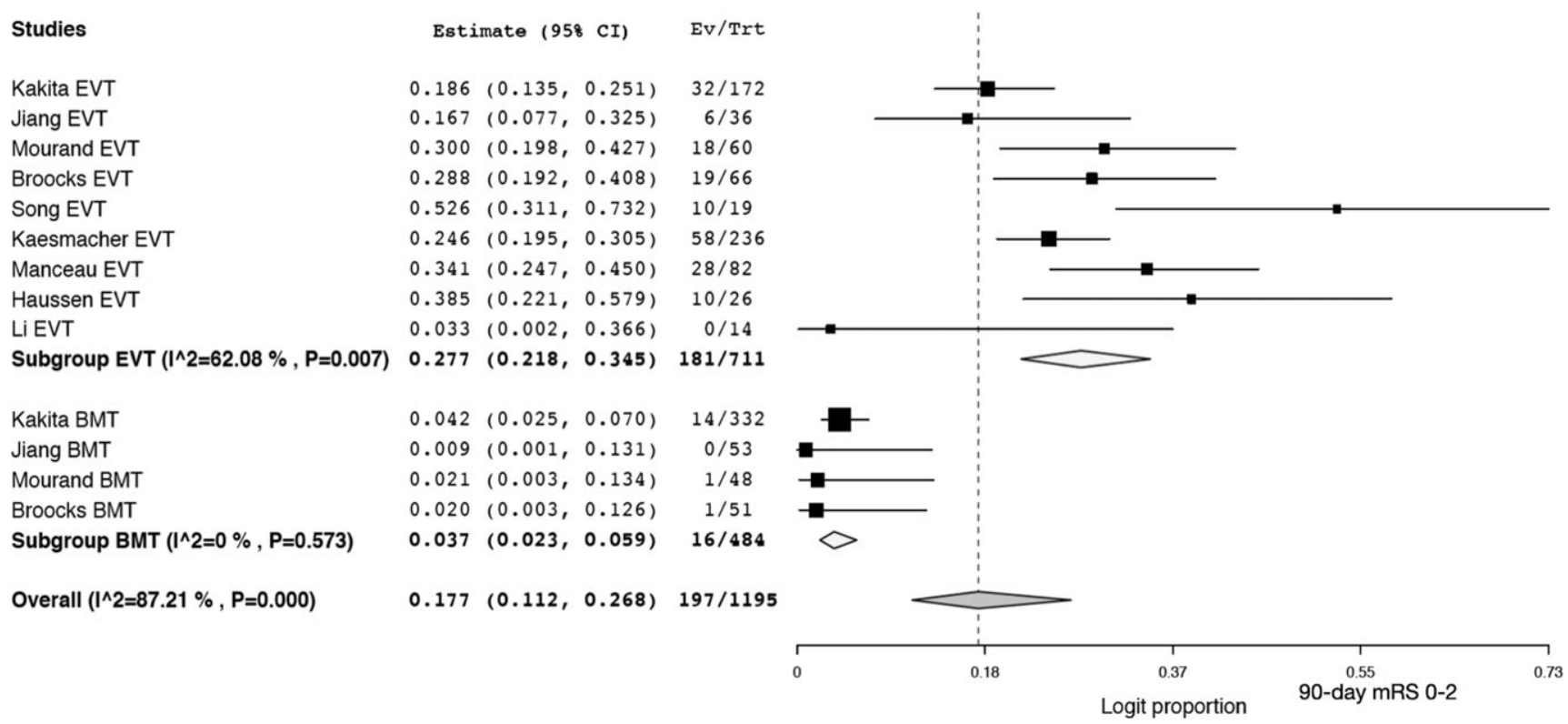

Figure 3: Forest plot of pooled proportion of patients with a 90-day $m R S$ of 0-2 for endovascular therapy (EVT) and best medical therapy (BMT).

ischemic cores. ${ }^{3-5}$ Low ASPECTS has been shown to predict intracranial hemorrhage after EVT. ${ }^{36,37}$ Thus, the difference in sICH rate $(9.2 \%$ vs $4.4 \%)$ is most likely accounted for by the low ASPECTS of our patients $(<6)$ compared to the ones included in the earlier trials (mean ASPECTS of 9). ${ }^{3-5}$ The previously reported $19 \%$ sICH rate in EVT patients with an ASPECTS of $<6$ from a subset of the HERMES collaboration ${ }^{12}$ was not corroborated by our review that only showed a $9.2 \%$ sICH rate. Similar to our findings, an earlier attempt at large vessel reperfusion with the use of intra-arterial thrombolytics (PROACT 2) also showed a sICH rate (10\%). Despite this, the patients randomized to the intervention arm still had superior functional outcomes at 90 days. ${ }^{38}$ The pooled mortality rates in our patients in both the EVT and best medical therapy arms of our review are almost twice that found in the HERMES collaboration. Lower ASPECTS scores implying less salvageable brain and a higher chance of a malignant infarct likely underlie this finding as well.

A previous meta-analysis tackling the effect of ASPECTS on the outcomes of EVT patients suggested futility of the intervention for patients with low ASPECTS. ${ }^{29}$ What our study reveals is that despite the relatively lower good (mRS of 0-2) 90-day outcomes $(27.7 \%)$ compared to the earlier trials $(46.0 \%)^{13}$ utilizing criteria that screened out large core infarct patients, there is still benefit compared to low ASPECTS patients only receiving best medical therapy who have a dismal $3.7 \%$ rate of good outcomes at 90 days.

Clinical benefit of EVT for stroke patients with low ASPECTS could for instance be strategic salvage of eloquent areas such as internal capsule and Rolandic cortex. Future directions in the use of ASPECTS for determining EVT eligibility should take into account that not all 10 points of the scoring system that correspond to different middle cerebral artery territories have the same clinical impact. In addition, reduction in net water uptake, a biomarker associated with the development of malignant edema, has also been shown to be decreased in low ASPECTS stroke patients achieving reperfusion after undergoing EVT. This implies that edema reduction may mediate the benefit seen in this subset of patients. ${ }^{39}$

ASPECTS relies on the ability of the reader to determine early ischemic changes, such as focal swelling and parenchymal hypoattenuation in the territory of the middle cerebral artery. ${ }^{40}$ It has been shown to have good interobserver reliability in its use for intra-arterial stroke treatment selection. ${ }^{41}$ However, a later study demonstrated limited interobserver agreement in scans taken less than 100 minutes from the known onset of symptoms. ${ }^{42}$ Likewise, two recent ASPECTS interrater agreement studies utilizing both CT and MRI focused on EVT candidates also found insufficient agreement between clinicians. ${ }^{43,44}$ Another modality used to determine the eligibility of patients for EVT, especially in the extended time period ( $>6$ hours), is perfusion scanning. Unlike, ASPECTS scoring which determines the core infarct based on radiologic changes in the brain parenchyma, perfusion scanning relies on quantifying blood flow to determine the extent of infarcted tissue. A study comparing the two modalities actually found that automated perfusion scanning overestimated the core size when compared to 24 hours post-EVT ASPECTS scans. ${ }^{45}$

The DEFUSE 3 and EXTEND study established the role of automated perfusion imaging (Rapid processing of PerfusIon and Diffusion [RAPID] software) for selection of patients eligible for medical and mechanical reperfusion. ${ }^{46,47}$ RAPID guides neurointerventionalists by effectively mapping out and ischemic core and salvageable penumbra. Because the software provides exact volume estimates for both core and penumbra, there is much less variability in interpretation. However, the added cost of the software for automated perfusion may pose a significant hurdle to public hospitals in developing nations eager to expand their endovascular program. Despite the limitations of ASPECTS, expanding the eligibility of large vessel occlusion ischemic strokes for EVT in terms of the scoring system may be a worthwhile endeavor, especially for these settings. In addition, certain peculiarities with perfusion imaging such as overestimation of penumbral size in patients with 
chronic ipsilateral carotid stenosis is not an issue for ASPECTS scoring because the latter interprets based on the morphology of the actual brain tissue. More recently, the prevalence of significant clinical-core mismatch and large core $(>70 \mathrm{cc})$ based on RAPID automated perfusion in patients with ASPECTS $\geq 6$ was found to be similar in both the early ( $<6$ hours) and late (6-24 hours). ${ }^{48}$ This new finding may expand the role of ASPECTS into the late window, especially in places with no access to perfusion imaging.

\section{Limitations}

The study has several limitations, the first being the marked heterogeneity found in the EVT group. Second, two of the four studies with data for median ASPECTS show a lower ASPECTS in the best medical therapy group compared to the EVT group ( 3 vs 5 ). This may account for the large difference in 90-day outcomes between the two groups as lower ASPECTS are predictive of worse clinical outcomes. ${ }^{49}$ Third, bias inherent to the retrospective nature of all the studies included could not be avoided. Fourth, the use of both MRI and CT in the determination of initial ASPECTS in the studies reviewed limits the applicability of the study. Disagreement between the two modalities for ASPECTS may be as high as $20 \% .^{50}$ Fifth, there were significantly more diabetic patients in the best medical therapy group. This may have contributed to their poorer outcomes. Sixth, the definition used for $\mathrm{sICH}^{26}$ was not uniform across all the studies included. Seventh, the mean onset to reperfusion time in the EVT group was less than 6 hours. Thus, the results have limited applicability to patients coming in beyond this time. Lastly, misclassification bias may result in some "low ASPECTS" patients actually having a "true" ASPECTS $>6$. Similarly, the converse will also have significant implications in the interpretation of our systematic review's findings. A comparison between the ASPECTS findings of a core laboratory and study investigators for an EVT trial found significant discrepancy between the scores. ${ }^{27}$ Ongoing randomized clinical trials for EVT on patients with large core infarcts that utilize a core laboratory with uniform parameters will hopefully provide more conclusive data on the subject. ${ }^{28,30-32}$. Only data from these studies can definitively establish if EVT is really effective in achieving superior outcomes in low ASPECTS patients. These studies will also hopefully shed light on difference in outcomes in the low ASPECTS subgroups, that is, ASPECTS of 0-2 and 3-5.

\section{Conclusions}

This meta-analysis of 9 studies including 1,196 patients demonstrates a trend toward higher sICH. Despite this, a significant proportion patients undergoing EVT still achieved good functional outcomes at 90 days. However, the results of the study should be interpreted with caution as all the studies included were observational studies which are inherently biased. Randomized controlled trials are needed to establish the utility of EVT for this subset of patients.

\section{Disclosures}

Dr. Bharatha has modest honoraria from Medtronic. Otherwise, the authors report no conflict of interest concerning the materials or methods used in this study or the findings specified in this paper.

\section{Contributors}

Study inception: JDBD, AAD, KP, AB. Data extraction: JDBD, GB, KP, AAD. Data analysis: JDBD, KP, AAD. Interpretation: JDBD, AAD, KP, JAH, KC, AK, AB. Initial draft of manuscript: JDBD, KP, AAD. Review and editing: JDBD, AAD, KP, JAH, KC, AK, AB. Supervision: JAH, KC, AK, AB

\section{SUPPLEMENTARY MATERIAL}

To view supplementary material for this article, please visit https://doi.org/10.1017/cjn.2020.71.

\section{REFERENCES}

1. Katan M, Luft A. Global burden of stroke. Semin Neurol. 2018; 38(2):208-211. doi: 10.1055/s-0038-1649503

2. World Health Organization: the top 10 causes of death, 2017. Available at: http://www.who.int/mediacentre/factsheets/fs310/ en/; accessed August 27, 2017.

3. Saver JL, Goyal M, Bonafe A, et al. Stent-retriever thrombectomy after Intravenous t-PA vs. t-PA Alone in Stroke. N Engl J Med. 2015;372(24):2285-2295. doi: 10.1056/NEJMoa1415061

4. Jovin TG, Chamorro A, Cobo E, et al. Thrombectomy within 8 hours after symptom onset in ischemic stroke. N Engl J Med. 2015;372(24):2296-2306. doi: 10.1056/NEJMoa1503780

5. Goyal M, Demchuk AM, Menon BK, et al. Randomized assessment of rapid endovascular treatment of ischemic stroke. N Engl J Med. 2015;372(11):1019-1030. doi: 10.1056/NEJMoa1414905

6. Campbell BCV, Mitchell PJ, Kleinig TJ, et al. Endovascular therapy for ischemic stroke with perfusion-imaging selection. N Engl J Med. 2015;372(11):1009-1018. doi: 10.1056/NEJMoa1414792

7. Berkhemer OA, Fransen PSS, Beumer D, et al. A randomized trial of intraarterial treatment for acute ischemic stroke. N Engl J Med. 2015;372(1):11-20. doi: 10.1056/NEJMoa1411587

8. Nogueira RG, Jadhav AP, Haussen DC, et al. Thrombectomy 6 to 24 hours after stroke with a mismatch between deficit and infarct. $\mathrm{N}$ Engl J Med. 2018;378(1):11-21. doi: 10.1056/NEJMoa1706442

9. Powers WJ, Rabinstein AA, Ackerson T, et al. 2018 Guidelines for the early management of patients with acute ischemic stroke: a guideline for healthcare professionals from the American Heart Association/American Stroke Association. Stroke. 2018;49(3): e46-e99. doi: 10.1161/STR.0000000000000158

10. Horsch AD, Dankbaar JW, van der Graaf Y, et al. Relation between reperfusion and hemorrhagic transformation in acute ischemic stroke. Neuroradiology. 2015;57(12):1219-1225. doi: 10.1007/ s00234-015-1577-6

11. Campbell BC V, Majoie CBLM, Albers GW, et al. Penumbral imaging and functional outcome in patients with anterior circulation ischaemic stroke treated with endovascular thrombectomy versus medical therapy: a meta-analysis of individual patient-level data. Lancet Neurol. 2019;18(1):46-55. doi: 10.1016/S14744422(18)30314-4

12. Román LS, Menon BK, Blasco J, et al. Imaging features and safety and efficacy of endovascular stroke treatment: a meta-analysis of individual patient-level data. Lancet Neurol. 2018;17(10): 895-904. doi: 10.1016/S1474-4422(18)30242-4

13. Goyal M, Menon BK, van Zwam WH, et al. Endovascular thrombectomy after large-vessel ischaemic stroke: a meta-analysis of individual patient data from five randomised trials. Lancet. 2016; 387(10029):1723-1731. doi: 10.1016/S0140-6736(16)00163-X

14. Logan C, Maingard J, Phan K, et al. Borderline Alberta stroke programme early CT score patients with acute ischemic stroke due to large vessel occlusion may find benefit with endovascular thrombectomy. World Neurosurg. 2018;110:e653-e658. doi: 10.1016/j.wneu.2017.11.068

15. Hungerford JP, Hyer M, Turk AS, et al. Impact of ASPECT scores and infarct distribution on outcomes among patients undergoing thrombectomy for acute ischemic stroke with the ADAPT technique. J Neurointerv Surg. 2017;9(9):823-829. doi: 10.1136/ neurintsurg-2016-012528 
16. Desilles J-P, Consoli A, Redjem H, et al. Successful reperfusion with mechanical thrombectomy is associated with reduced disability and mortality in patients with pretreatment diffusion-weighted imaging-Alberta Stroke Program early computed tomography score $\leq 6$. Stroke. 2017;48(4):963-969. doi: 10.1161/STROKEAHA. 116.015202

17. Kim SK, Yoon W, Park MS, Heo TW, Baek BH, Lee YY. Outcomes are not different between patients with intermediate and high DWI-ASPECTS after stent-retriever embolectomy for acute anterior circulation stroke. Am J Neuroradiol. 2016;37(6): 1080-1085. doi: 10.3174/ajnr.A4663

18. Ohta T, Morimoto M, Okada K, et al. Mechanical thrombectomy in anterior circulation occlusion could be more effective than medical management even in low DWI-ASPECTS patients. Neurol Med Chir (Tokyo). 2018;58(4):156-163. doi: 10.2176/nmc.oa.2017-0203

19. Bracard S, Ducrocq X, Mas JL, et al. Mechanical thrombectomy after intravenous alteplase versus alteplase alone after stroke (THRACE): a randomised controlled trial. Lancet Neurol. 2016; 15(11):1138-1147. doi: 10.1016/S1474-4422(16)30177-6

20. Moher D, Liberati A, Tetzlaff J, Altman DG. Preferred reporting items for systematic reviews and meta-analyses: the PRISMA statement. PLoS Med. 2009;6(7):e1000097. doi: 10.1371/journal. pmed. 1000097

21. Stroup DF. Meta-analysis of Observational Studies in Epidemiology: A Proposal for Reporting. JAMA. 2000;283(15):2008. doi: 10.1001/ jama.283.15.2008

22. Murad MH, Sultan S, Haffar S, Bazerbachi F. Methodological quality and synthesis of case series and case reports. BMJ Evidence-Based Med. 2018;23(2):60-63. doi: 10.1136/bmjebm2017-110853

23. Wells GA, Shea B, Connell D, et al. The Newcastle-Ottawa Scale (NOS) for assessing the quality of nonrandomised studies in meta-analyses. Ottawa, Canada: Ottawa Hospital Research Institute, 2014. www.ohri.ca/programs/clinical_epidemiology/oxford.asp.

24. Hozo SP, Djulbegovic B, Hozo I. Estimating the mean and variance from the median, range, and the size of a sample. BMC Med Res Methodol. 2005;5(1):13. doi: 10.1186/1471-2288-5-13

25. Kakita H, Yoshimura S, Uchida K, et al. Impact of endovascular therapy in patients with large ischemic core. Stroke. 2019; 50(4):901-908. doi: 10.1161/STROKEAHA.118.024646

26. Yaghi S, Willey JZ, Cucchiara B, et al. Treatment and outcome of hemorrhagic transformation after intravenous alteplase in acute ischemic stroke: a scientific statement for healthcare professionals from the American Heart Association/American Stroke Association. Stroke. 2017;48(12). doi: 10.1161/STR.0000000000000152

27. Fahed R, Ben Maacha M, Ducroux C, et al. Agreement between core laboratory and study investigators for imaging scores in a thrombectomy trial. J Neurointerv Surg. 2018;10(12):e30-e30. doi: 10. 1136/neurintsurg-2018-013867

28. Yoshimura S. Randomized controlled trial of endovascular therapy for acute large vessel occlusion with large ischemic core. Available at: https://clinicaltrials.gov/ct2/show/NCT03702413; accessed September 2, 2019.

29. Phan K, Saleh S, Dmytriw AA, et al. Influence of ASPECTS and endovascular thrombectomy in acute ischemic stroke: a metaanalysis. J Neurointerv Surg. 2019;11(7):664-669. doi: 10.1136/ neurintsurg-2018-014250

30. Bendszus M. Efficacy and safety of thrombectomy in stroke with extended lesion and extended time window (Tension). ClinicalTrials.gov, 2019. Available at: https://clinicaltrials.gov/ ct2/show/NCT03094715; accessed July 23, 2019.

31. Zaidat OO. The TELSA trial: Thrombectomy for Emergent Salvage of Large Anterior Circulation Ischemic Stroke (TESLA). Available at: https://clinicaltrials.gov/ct2/show/NCT03805308; accessed September 2, 2019.

32. IN EXTREMIS: Large Stroke Therapy Evaluation - ASPECT 0-5. Available at: https://www.inextremis-study.com/copie-de-mosterationale-1; accessed September 2, 2019.

33. Haussen DC, Dehkharghani S, Rangaraju S, Rebello LC, Bouslama M, Grossberg JA, Anderson A, Belagaje S, Frankel M, Nogueira RG. Automated CT perfusion ischemic core volume and noncontrast CT ASPECTS (Alberta Stroke Program Early CT Score). Stroke. 2016;47(9):2318-2322.

34. Li W, Li S, Dai M, Wang S, Xiong Y. Comparisons of ASPECTS 5 and 6 for endovascular treatment in anterior circulation occlusive stroke. Interv Neuroradiol. 2017;23(5):516-520. doi: 10.1177/ 1591019917720920

35. Goyal M, Menon BK, van Zwam WH, et al. Endovascular thrombectomy after large-vessel ischaemic stroke: a meta-analysis of individual patient data from five randomised trials. Lancet. 2016; 387(10029):1723-1731. doi: 10.1016/S0140-6736(16)00163-X

36. Nawabi J, Kniep H, Schön G, et al. Hemorrhage after endovascular recanalization in acute stroke: lesion extent, collaterals and degree of ischemic water uptake mediate tissue vulnerability. Front Neurol. 2019;10. doi: 10.3389/fneur.2019.00569

37. Raychev R, Saver JL, Jahan R, et al. The impact of general anesthesia, baseline ASPECTS, time to treatment, and IV tPA on intracranial hemorrhage after neurothrombectomy: pooled analysis of the SWIFT PRIME, SWIFT, and STAR trials. J Neurointerv Surg. June 2019:neurintsurg-2019-014898. doi: 10.1136/neurintsurg-2019-014898

38. Furlan A, Higashida R, Wechsler L, et al. Intra-arterial prourokinase for acute ischemic stroke. JAMA. 1999;282(21):2003. doi: 10. 1001/jama.282.21.2003

39. Broocks G, Hanning U, Flottmann F, et al. Clinical benefit of thrombectomy in stroke patients with low ASPECTS is mediated by oedema reduction. Brain. March 2019. doi: 10.1093/ brain/awz057

40. Pexman JH, Barber PA, Hill MD, et al. Use of the Alberta Stroke Program Early CT Score (ASPECTS) for assessing CT scans in patients with acute stroke. AJNR Am J Neuroradiol. 2001;22(8): 1534-1542. http://www.ncbi.nlm.nih.gov/pubmed/11559501.

41. Gupta AC, Schaefer PW, Chaudhry ZA, et al. Interobserver reliability of baseline noncontrast CT Alberta Stroke Program Early CT score for intra-arterial stroke treatment selection. Am J Neuroradiol. 2012;33(6):1046-1049. doi: 10.3174/ajnr. A2942

42. Naylor J, Churilov L, Rane N, Chen Z, Campbell BCV, Yan B. Reliability and utility of the alberta stroke program early computed tomography score in hyperacute stroke. J Stroke Cerebrovasc Dis. 2017;26(11):2547-2552. doi: 10.1016/j.jstrokecerebrovasdis. 2017.05.042

43. Farzin B, Fahed R, Guilbert F, et al. Early CT changes in patients admitted for thrombectomy. Neurology. 2016;87(3):249-256. doi: 10.1212/WNL.0000000000002860

44. Fahed R, Lecler A, Sabben C, et al. DWI-ASPECTS (DiffusionWeighted Imaging-Alberta Stroke Program Early Computed Tomography Scores) and DWI-FLAIR (Diffusion-Weighted Imaging-Fluid Attenuated Inversion Recovery) mismatch in thrombectomy candidates. Stroke. 2018;49(1):223-227. doi: 10.1161/STROKEAHA.117.019508

45. Tsang ACO, Lenck S, Hilditch C, et al. Automated CT perfusion imaging versus non-contrast $\mathrm{CT}$ for ischemic core assessment in large vessel occlusion. Clin Neuroradiol. 2020;30(1):109-114. doi: 10.1007/s00062-018-0745-6

46. Ma H, Campbell BCV, Parsons MW, et al. Thrombolysis guided by perfusion imaging up to 9 hours after onset of stroke. N Engl J Med. 2019;380(19):1795-1803. doi: 10.1056/NEJMoa1813046

47. Albers GW, Marks MP, Kemp S, et al. Thrombectomy for stroke at 6 to 16 hours with selection by perfusion imaging. N Engl J Med. 2018;378(8):708-718. doi: 10.1056/NEJMoa1713973

48. Desai SM, Tonetti DA, Molyneaux BJ, et al. Interaction between time, ASPECTS, and clinical mismatch. J Neurointerv Surg. April 2020:neurintsurg-2020-015921. doi: 10.1136/neurintsurg-2020015921

49. Hill MD. Thrombolysis for acute ischemic stroke: results of the Canadian alteplase for Stroke Effectiveness Study. Can Med Assoc J. 2005;172(10):1307-1312. doi: 10.1503/cmaj.1041561

50. Hui FK, Obuchowski NA, John S, et al. ASPECTS discrepancies between CT and MR imaging: analysis and implications for triage protocols in acute ischemic stroke. J Neurointerv Surg. 2017; 9(3):240-243. doi: 10.1136/neurintsurg-2015-012188 